\title{
Antibacterial Activity of Saponin and Alkaloidal Extracts of Whole Plant of Phyllanthus niruri L., (Syn. P. franternus Webster)
}

\author{
Victor Adeyinka Ajibade ${ }^{a *}$ and Oladiran Famurewa ${ }^{b}$ \\ ${ }^{a}$ Microbiology Unit, Department of Science Technology, Federal Polytechnic, P.M.B 5351, Ado-Ekiti, Nigeria \\ ${ }^{b}$ Department of Biological Sciences, Faculty of Science, Osun State University, \\ P.M.B. 4494, Oke-Baale, Osogbo, Nigeria
}

(received April 2, 2010; revised June 7, 2010; accepted August 23, 2010)

\begin{abstract}
Saponins identified as phylagenin-13-O- $\alpha$-D-glucopyranoside and phylangenin-25-O- $\beta$-Dglucopyranoside and alkaloid, extracted from the whole plant of Phyllanthus niruri, were tested for minimum inhibitory concentration (MICs) against Staphylococus aureus, Staphylococus pyrogenes, Escherichia coli, Salmonella typhi and Klebsiella pneumoniae. MIC of saponin against S. aureus SSH22 and SSH23 ranged from 5-15 $\mu \mathrm{g} / \mathrm{mL}$, and against E. coli OAUTH71 and K. pneumoniae OAUTH 54, from $15-60 \mu \mathrm{g} / \mathrm{mL}$. MICs increased with the increase in concentration of cells used in the inoculum. S. aureus SSH22 exhibited a paradoxical biphasic response to saponin in nutrient broth, whereas bacterial activity against E. coli SSH31 increased with concentration up to the highest concentration of saponin tested. Activity against E. coli OAUTH71 was more pronounced in the phosphate-buffered saline than in the nutrient broth. The other active compound extracted (alkaloid) gave MIC values between 200 and $600 \mu \mathrm{g} / \mathrm{mL}$.
\end{abstract}

Keywords: Phyllanthus niruri, saponin, alkaloid, antibacterial activity

\section{Introduction}

Extracts of many plants are known to elicit certain reactions in human body when applied in a prescribed manner including Phyllanthus niruri L., (Syn. $P$. franternus Webster) belonging to the family Euphorbiaceae. It has been claimed to be an excellent remedy for jaundice and hepatitis (Tabasum et al., 2005; Qudhia and Tripathi, 2002). The plant is considered analgesic, aperitif, digestive, emmanagogue, laxative and stomachic tonic (Khanna et al., 2002) and is helpful in treating oedema, anorexia and diabetes (George and Pamplona-Roger, 2002.). Its roots, leaves, fruits, milky juice as well as the whole plant are used as medicine. Recently, lignansniranthin, nirtetralin and phyltetralin have been isolated from the leaves (Tabasum et al., 2005). Many of the active constituents found in the plant are biologically active lignans, glycosides, flavonoids, saponins, alkaloids, ellagitannins and phenylpropanoids (Dhar et al., 1968); common lipids sterols and flavonoids also occur in the plant (Barros et al., 2003). Alkaloids are organic nitrogencontaining compounds found in $20-30 \%$ of vascular plants and at lower doses, are useful pharmacologically. These compounds are renowned for their potent pharmacological activities (Sharma and Gupta, 1994).

*Author for correspondence; E-mail: ajibvijay@yahoo.com
Tiny amounts of some of them can immobilise even an elephant; others can be clinically used as analgesic, antimalarial, and antispasmodic agents, for pupil dilation, and treatment of hypertension, mental disorders and tumours. Morphine, codeine, atropine and ephedrine are just a few of the plant alkaloids currently used in medicine (Naik and Juvekar, 2003). Other alkaloids, including cocaine, nicotine and caffeine, enjoy a widespread non-medical use as stimulant or sedative (Naik and Juvekar, 2003). Some alkaloids are medically useful for the cure of human diseases e.g. atropine in treatment of bronchial asthma (Natarraj, 2000); intestinal and biliary colic, and to dilate pupil of the eye (Naik and Juvekar, 2003). Saponins are glycosides with a distinctive foaming characteristic. They are found in various parts of the plant leaves, stems, roots, bulbs, flowers and fruits. The name "saponin" originated from soapwort plant (saponaria), the root of which was used historically as a soap. Saponins are believed to be useful in the human diet for controlling cholesterol, but some (including those produced by the soapberry) are poisonous if swallowed and can cause urticaria (skin rash) in many people (Marston et al., 2000). Digitalis type saponins strengthen heart muscle contractions, causing the heart to work more efficiently (Haridas et al., 2001). Saponins inhibit some kind of cancerous cell growth in 
animals particularly in cases of lung and blood cancers, without killing normal cells (Ray, 2007).

\section{Materials and Methods}

Collection of plant material. Phyllanthus niruri was collected from shrubs around the Federal Polytechnic Compound, Ado-Ekiti, Nigeria during the months of July to September 2008 and was identified at the Department of Plant Science, University of Ado-Ekiti, Nigeria. A voucher specimen was deposited at the herbarium of the Department of Science Technology, Federal Polytechnic, Ado-Ekiti. The sample used for the analysis was air-dried at room temperature of \pm 28 ${ }^{\circ} \mathrm{C}$ and pulverized.

Test organisms. The following bacteria were used in the study: Bacillus subtilis NCTC 8263, Staphylococcus aureus SSH22, S. aureus SSH23, Streptococcus pyogenes SSH43, Escherichia coli SSH31, Klebsiella pneumoniae OAUCH54 and Salmonella typhi SSH45, which were obtained from clinical isolates at the University Teaching Hospital (SSH), Ado-Ekiti, and Specialist Laboratory of the Centre for Disease Control (SLT), Ile-Ife and Obafemi Awolowo University Teaching Hospital (OAUTH), Ile-Ife Annex, Wesley, Ilesa, Nigeria. They were authenticated using conventional methods. The organisms were stored on the nutrient agar (LAB) slant at $4{ }^{\circ} \mathrm{C}$ until required for use.

The media used were: oxoid nutrient broth (Basingstoke, UK) which was solidified with 1.5\% Lab M agar No. 1 (Amersham Basingstoke, UK) to make nutrient agar, oxoid iso-sensitest agar and minimal salts (DM) Davis Mingiolis medium which was solidified with 1.5\% Lab M agar No. 1 to make solid media.

Extraction of crude alkaloid. The method of Naik and Juvekar (2003) was employed for the extraction. The dried, coarsely powdered whole plant of $P$. niruri (200 g) was moistened with 25\% ammonium hydroxide, allowed to stand overnight and then Soxhlet extracted with $95 \%$ ethanol. After concentraction under vacuum, the syrup residue ( $30 \mathrm{~g}$ ) was treated with conc. $\mathrm{HCl}$. The acidic filtrate was washed with benzene, made basic ( $\mathrm{pH} 10$ ) with $25 \%$ ammonium hydroxide and extracted with chloroform to collect the alkaloidal fraction (2 g).

Extraction of crude saponin. The saponin was extracted according to the method described by
Marston et al. (2000). The milled plant (170 g) was defatted using $700 \mathrm{~mL}$ of petroleum ether for $72 \mathrm{~h}$ using soxhlet for about $24 \mathrm{~h}$. Methanol $(700 \mathrm{~mL})$ was used to extract saponin from the defatted sample and the residue was left overnight under reflux at $70^{\circ} \mathrm{C}$. It was then filtered and the filtrate was evaporated to dryness. The yield was dissolved in distilled water $(300 \mathrm{~mL})$ and in the ratio of 1:1 with methanol placed in a separating funnel. The set up was left for three days when two layers were formed. The bottom layer was removed and the upper layer, which is the crude saponin, was poured into an evaporating dish and dried by evaporation for 2 weeks.

Bacteriological assay. The isolated crude extracts of the plant were investigated biologically and the active compounds were detected and purified. The bioassay monitoring of fractions was undertaken using agar disc diffusion technique (Denni and Hussain, 1991). Aliquots $(20 \mu \mathrm{L})$ of the extracts were placed on susceptibility test discs. These were then applied to the surface of overdried nutrient agar plates, which had been seeded with an overnight culture of test organism. Culture plates were incubated overnight at $37{ }^{\circ} \mathrm{C}$ and zones of inhibition were estimated semi-quantitatively. Gentamicin sulphate (Nicholas Laboratories, UK) and Ampicillin (Beecham) were used as positive controls.

Characterization of saponin. The crude saponin was characterized using ${ }^{13} \mathrm{C}$ NMR spectra described by Olugbade et al. (2000). Optical rotations at $20^{\circ} \mathrm{C}$ were taken on a Perkin-Elmer 241 polarimeter. Spectra were recorded as follows: pulse of $92.9^{\circ}$, total time of $9 \mathrm{~h}$ 20 min $51 \mathrm{sec}$; WALTZ-16 modulated and 19237 repetitions. Infra-red spectra were obtained as nujol mull on Pye Unicam SP 300 Infrared Spectrophotometer. The $\mathrm{H}^{1}$-NMR was taken in deuterochloroform with tetramethylsaline (TMS) as internal standard using a Bruker WH $300 \mathrm{Mhz}$ spectrophotometer employing Fourier transform techniques. The MS using the electron impart technique was obtained by direct insertion at an ionization voltage of $70 \mathrm{eV}$ using AE-MS 902 (V.G. Micromass Ltd., Manchester, UK). The mass spectrophotometer was fitted with a DS-55 computer data output at inlet temperature of 170 $240{ }^{\circ} \mathrm{C}$.

\section{Results and Discussion}

Four bacterial strains were used for determination of the antibacterial activities (Table 1). S. aureus SSH22, 
S. aureus SSH23, E. coli SSH31 and K. pneumoniae OAUCH 54. The activities of the initial solvent extracts and the active compounds were compared with the standard antibiotics, gentamicin and ampicillin.

Table 1. Bacteriological monitoring of active compound isolates

\begin{tabular}{|c|c|c|c|c|c|}
\hline \multirow{2}{*}{$\begin{array}{l}\text { Test } \\
\text { extract } \\
\text { (fractions) }\end{array}$} & \multirow{2}{*}{$\begin{array}{l}\text { Concen- } \\
\text { tration }\end{array}$} & \multicolumn{4}{|c|}{ Zone of inhibition (mm) } \\
\hline & & $\begin{array}{l}\text { S.aureus } \\
\text { SSH23 }\end{array}$ & $\begin{array}{l}\text { S. aureus } \\
\text { SSH22 }\end{array}$ & $\begin{array}{l}\text { E. coli } \\
\text { SSH31 }\end{array}$ & $\begin{array}{l}\text { K. pneumo- } \\
\text { niae OAUTH54 }\end{array}$ \\
\hline PEE & $20 \% \mathrm{v} / \mathrm{v}$ & 10.0 & 10.0 & 10.0 & 5.0 \\
\hline $\mathrm{CH}$ & $20 \% \mathrm{v} / \mathrm{v}$ & 15.0 & 15.0 & 10.0 & 10.0 \\
\hline SAP & $\begin{array}{l}5 \mu \mathrm{g} \\
20 \mu \mathrm{g}\end{array}$ & $\begin{array}{l}10.0 \\
26.0\end{array}$ & $\begin{array}{l}5.0 \\
26.0\end{array}$ & $\begin{array}{l}5.0 \\
15.0\end{array}$ & $\begin{array}{l}- \\
5.0\end{array}$ \\
\hline ALK & $\begin{array}{l}200 \mu \mathrm{g} \\
600 \mu \mathrm{g}\end{array}$ & $\begin{array}{l}15.0 \\
\text { NT }\end{array}$ & $\begin{array}{l}15.0 \\
\text { NT }\end{array}$ & $\begin{array}{l}- \\
10.0\end{array}$ & - \\
\hline GEN & $2 \mu \mathrm{g}$ & 10.0 & 10.0 & 10.0 & 5.0 \\
\hline AMP & $5 \mu \mathrm{g}$ & 5.0 & 5.0 & 5.0 & 5.0 \\
\hline MET & $50 \% \mathrm{v} / \mathrm{v}$ & - & - & - & - \\
\hline
\end{tabular}

$\mathrm{PEE}=$ petroleum ether extract; $\mathrm{CH}=$ chloroform; $\mathrm{SAP}=$ saponin; ALK = alkaloid; GEN = gentamicin; AMP = ampicillin; $\mathrm{MET}=$ methanol; $\mathrm{NT}=$ not traced.

It was observed that saponin at $5 \mu \mathrm{g} / \mathrm{mL}$ and $20 \mu \mathrm{g} / \mathrm{mL}$ had activity against $S$. aureus SSH22, S. aureus SSH23 and $E$. coli SSH31 within the range of the standard antibiotics used. However, K. pneumoniae OAUTH54 showed resistance to the saponin at a concentration of $5 \mu \mathrm{g} / \mathrm{mL}$. Five compounds were extracted from P. niruri using column chromatography together with monitoring of the solvent fractions using TLC and an antimicrobial assay. The compounds, which were found in the petroleum ether and chloroform fractions, were identified by MS, UV, IR and ${ }^{13} \mathrm{C}-\mathrm{NMR}$ as phylagenin$13-O-\alpha-D-$ glucopyranoside and phylangenin-25-O- $\beta$ D-glucopyranoside saponin, which showed the appearance of the anomeric C-1 signal at 105 ppm and C-7, at $98 \mathrm{ppm}$, alkaloid and another compound that is yet to be identified.

All the fractions investigated were active in the antimicrobial assays (Table 1). Saponin isolated from P. niruri had previously been shown to be bactericidal to E. coli (Calbo et al., 2006). However, antibacterial activities against $E$. coli and $S$. typhi have been previously reported for alkaloid (Naik and Juvekar, 2003).

The effect of saponin on some bacterial strains was, therefore, investigated further (Table 2). The MICs of the saponin extract against the test bacteria were determined using three different concentrations of the inoculum (undiluted, over-night culture, and diluted $10^{-2}$ and $10^{-4}$ ). The first two concentrations of the cells gave confluent growth on nutrient agar, whereas application of $20 \mu \mathrm{L}$ of the $10^{-4}$ dilution gave about 20 isolated colonies per application. MICs of gram positive organisms ranged between $3 \mu \mathrm{g} / \mathrm{mL}$ for the $10^{-4}$ dilution of $S$. aureus SSH22 and $30 \mu \mathrm{g} / \mathrm{mL}$ against undiluted S. pyogenes SSH43. For gram-negative organisms, the range of MICs was between $15 \mu \mathrm{g} / \mathrm{mL}$ for E. coli OAUTH71 (10 $10^{-4}$ dilution) to over $60 \mu \mathrm{g} / \mathrm{mL}$ for S. typhi SSH45 (Table 2). From these results, it was concluded that saponin had activity on these tests bacteria within the range of standard antibiotics used as control. The effect of saponin on these bacterial strains was, therefore, investigated further.

Table 2. Minimum inhibitory concentration (MIC) of saponin in nutrient agar at various concentrations of inoculum*

\begin{tabular}{|c|c|c|c|}
\hline \multirow[t]{3}{*}{ Test organisms } & \multicolumn{3}{|c|}{ Inoculum density (cfu) } \\
\hline & $2 \times 10^{-4}$ & $2 \times 10^{-2}$ & 20 \\
\hline & \multicolumn{3}{|c|}{ MIC $(\mu \mathrm{g} / \mathrm{mL})$} \\
\hline S. aureus SSH23 & 5 & 3 & 3 \\
\hline S. aureus SSH22 & 15 & 5 & 5 \\
\hline B. subtilis & 15 & 15 & 5 \\
\hline S. pyogenes SSH33 & 30 & 15 & 15 \\
\hline K. pneumoniae & 60 & 45 & 30 \\
\hline S. typhi SSH45 & $>60$ & 60 & 45 \\
\hline
\end{tabular}

* = MICs based on triplicate results.

Bactericidal activity of saponin. Data obtained from viable counts of S. aureus SSH22 and E. coli SSH31, suspended in nutrient broth containing saponin, confirmed the MICs of the extract in nutrient agar (Table 2). The bactericidal activity against $S$. aureus SSH22 commenced at concentrations above MICs ( $5 \mu \mathrm{g} / \mathrm{mL}$ ) and increased with the increase in the concentration of the extract (Fig. 1). However, the extract became less active towards $\mathrm{S}$. aureus $\mathrm{SSH} 22$ at concentration above $60 \mu \mathrm{g} / \mathrm{mL}$, giving a biphasic response (Fig. 2).

The bactericidal activity of the saponin extract against E. coli SSH31 in nutrient broth increased with the concentration of the extract (Fig. 3). No biphasic response was seen. The extract was more active in DM basal salt solution than in nutrient broth; $30 \mu \mathrm{g} / \mathrm{mL}$ was highly bactericidal in DM salt solution (Fig. 4), 
whereas it was only bacteriostatic in nutrient broth (Fig. 3), corresponding to the MIC determined in the nutrient agar (Table 1).

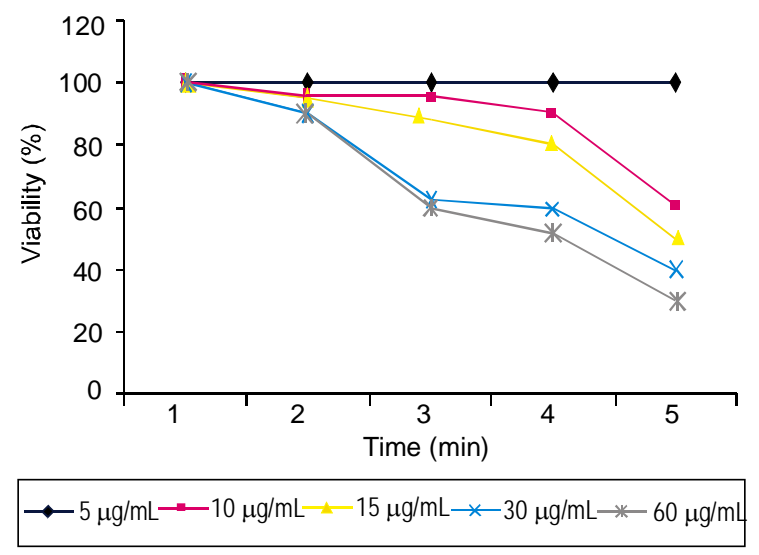

Fig. 1. Bactericidal activities of various concentrations of saponin in nutrient broth against S. aureus SSH22.

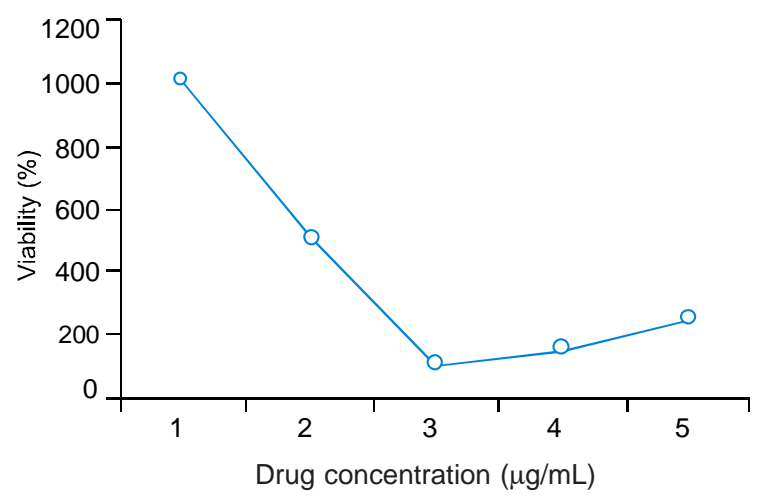

Fig. 2. Biphasic response of $S$. aureus to increasing concentrations of saponin in nutrient broth. Data plotted are survival levels after $270 \mathrm{~min}$ exposure $(1 \mu \mathrm{g} / \mathrm{mL}=10 \mu \mathrm{g} / \mathrm{mL})$.

Antibacterial activity of the extracts of saponin and alkaloids has been previously reported (Naik and Juvekar, 2003; Unander et al., 1990). The NMR and IR characterization of the saponin extract gave a spectra which identified the extract as phylagenin-13O- $\alpha$-D-glucopyranoside and phylangenin-25-O- $\beta$-Dglucopyranoside saponin. (Agrawal et al., 1985). In view of the antimicrobial activity of this extract, complete structural elucidation would be of interest.

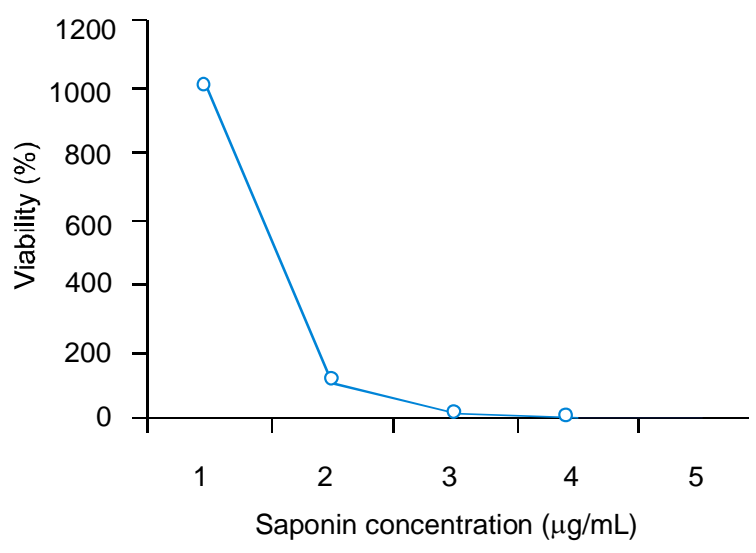

Fig. 3. Absence of biphasic response of E. coli SSH31 when exposed to increasing concentration of saponin in nutrient broth (data as in Fig. 2).

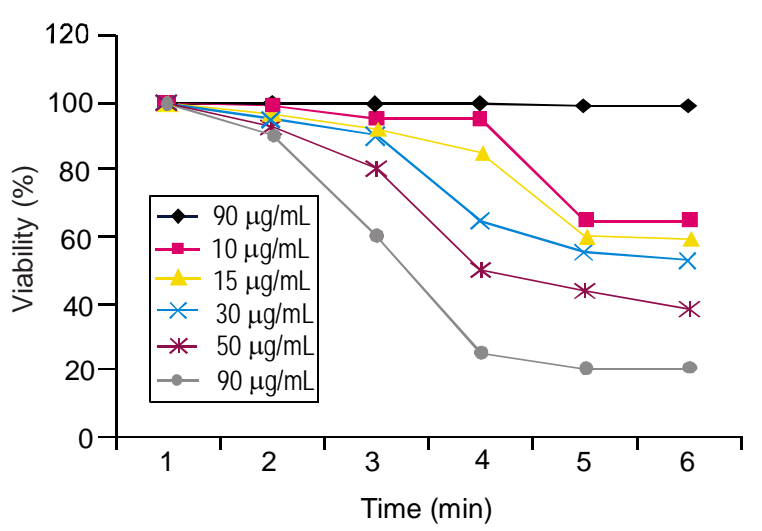

Fig. 4. Activity of saponin in Davis Mingiolis basal salt solution against $E$. coli SSH31.

The antibacterial activity of saponin is of some interest since it was effective at concentrations as low as $3 \mu \mathrm{g} / \mathrm{mL}$ against $S$. aureus SSH22 (Table 2). This concentration was of the same order of magnitude as the MIC determined for Gentamicin and Ampicillin (Table 2) and reported for other standard antibiotics such as chloramphenicol, penicillin, streptomycin or erythromycin (Kazakova et al., 2005). Increase in MICs produced by increasing the cell density of the inocula (Table 2) is similar to the observations of George and Pamplona-Roger (2002) of the antibacterial activity of 4-quinolone. Similarly, the suggestion that the response of S. aureus SSH22 to the drug is biphasic (Fig. 3) could be due to inhibition of RNA and protein synthesis by high concentrations of the extract, which 
is believed to be responsible for the biphasic response of antibacterial activity of quinolone (Marston et al., 2000). The bactericidal activity of saponin extract observed against $E$. coli SSH31 in phosphate buffered saline indicates that the extract is still bactericidal towards cells in which cell division is inhibited. This is similar to the observations of Naik and Juvekar (2003) regarding the bactericidal activities of the fluoroquinolone, ciprofloxacin and norfloxacin and in contrast to the activity of the parent compound nalidixic acid, which requires cell division for activity.

The data obtained in this study have led to the conclusion that the saponin content of P. niruri is responsible for the significant antibacterial effect of this plant on a wide range of organisms. This may explain some of the ethnopharmacological claims for this plant, especially its application as poultice for the treatment of certain types of ulcers (Barros et al., 2003), spleen disorders (Barros et al., 2003), superficial wounds (Khanna et al., 2002 ), chronic dysentery, asthma, jaundice (George and Pamplona-Roger, 2002), hepatitis B (Unander et al., 1990), as a cold infusion in the treatment of dysentery, typhoid fever (George and Pamplona-Roger, 2002), swellings and mange sores as well as having proven antihepatotoxic, antispasmodic, antiviral, bactericidal, diuretic, febrifugal and hypoglycaemic activities.

\section{References}

Agrawal, P.K., Jain, D.C., Gupta, R.K., Thakur, R.S. 1985. Carbon- ${ }^{13}$ NMR spectroscopy of steroidal sapogenins and steroidal saponins. Phytochemistry, 24: 2479-2496.

Barros, M.E., Schor, N., Boin, M.A. 2003. Effect of an aqueous extract from Phyllanthus niruri on calcium oxalate crystallization in vitro. Urological Research, 30: 367-373.

Calbo, E., Romani, V., Xercavins, M., Gomez, L., Vidal, C.G., Quintana, S., Vila, J. 2006. Risk factors for community-onset urinary tract infections due to Escherichia coli harbouring extended-spectrum beta-lactamases. Journal of Antimicrobial Chemotherapy, 57: 780-783.

Denni, Y., Hussain, H. 1991. Screening for antimicrobial activity and for alkaloids of Nauclea latifolia. Journal of Ethnopharmacology, 35: 91-96.

Dhar, M.L., Dhar, M.M., Dhawan, B.N., Mehrotra, B.N., Ray, C. 1968. Screening of Indian plants for biological activity. Indian Journal of Experimental Biology, 4: 232-247.

George, D., Pamplona-Roger, M.D. 2002. Encyclopaedia of Medicinal Plants, Inter-American Publishing Association (IADPA), USA.

Haridas, V., Higuchi, M., Jayatilake, G.S., Bailey, D., Mujoo, K., Blake, M.E., Arntzen, C.J., Gutterman, J.U. 2001. Avicins: Triterpenoid saponins from Acacia victoriae (Bentham) induce apoptosis by mitochondrial perturbation. Proceedings of the National Academy of Sciences USA, 98: 5821-5826.

Kazakova, S.V., Hageman, J.C., Matava, M., Srinivasan, A., Phelan, B., Garfinkel, T., Boo, S., McAllister, S., Anderson, J., Jensen, D., Dodson, D., Lonsway, D., McDougal, L.K., Arduino, M., Fraser, V.J., Killgore, G., Tenover, F.C., Cody, S., Jernigan, D.B. 2005. A clone of Methicillin-resistant Staphylococcus aureus among professional football players. New England Journal of Medicine, 352: 468-475.

Khanna, A.K., Rizvi, F., Chander, R. 2002. Lipid lowering activity of Phyllanthus niruri in hyperlipemic rats. Journal of Ethnopharmacology, 82: 19-22.

Marston, A., Wolfender, J.-L., Hostettmann, K. 2000. Analysis and isolation of saponin from plant materials. In: Saponin in Food, Feedstuffs and Medicinal Plants. Annual Proceeding of the Phytochemical Society of Europe, W. Oleszek and A. Marston (eds.), vol. 45, pp. 1-12, Kulwer Academic Publishers, The Netherlands.

Naik, A.D., Juvekar, A.R. 2003. Effects of alkaloid extract of Phyllanthus niruri on HIV replication. Indian Journal of Medical Science, 57: 387-393.

Natarraj, C.G. 2000. Role of herbal extracts in HIV infected patients, Proceedings of International Congress on Ayurveda, 207.

Olugbade, T.A., Ogundaini, A., Birlirakis, N., Pais, M., Martin, M.-T. 2000. Petersaponins III and IV Triterpenoid saponins from Petersianthus macrocarpus. Journal of Natural Products, 63: 716-719.

Qudhia, P., Tripathi, R.S. 2002. Prospect for cultivation of medicinal plants in Chattisgarh, India. In: Series Recent Progress in Medicinal Plants, Crops Improvement, Production Technology, Trade and Commerce, vol. 5, pp. 211-236, Sci. Tech. Publishers, USA. 
Ray, S.M.D. 2007. The sapogenin of the seed of flour lupin species. Journal of Plant Food, 3: 181-186.

Sharma, J.R., Gupta, M.M. 1994. Genetic and chemical analysis for alkaloids. In: Modern Methods of Plant Analysis-Alkaloids, H. F. Linsken and J. F. Jackson (eds.), vol. 15, pp. 216-234, Springer Verlag, Berlin, Germany.

Tabasum, N., Chatterrvedi, S., Aggrawal, S.S., Ahmed, N. 2005. Hepatoprotective studies of Phyllanthus niruri on paracetamol-induced liver cell damage in albino mice. Experimental Medicine, 12: 211212.

Unander, D.W., VenKateswaran, P.S., Millman, I., Bryan, H.H., Blumberg, B.S. 1990. Phyllanthus species: Sources of new antiviral compounds. In: Advances in New Crops, J. Janick and J. E. Simon (eds.), pp. 518-521, Timber Press, Portland, OR. 